\title{
DA ÉTICA PARA A JUSTIÇA ATRAVÉS DO DIREITO: ENTRE A RESPONSABILIDADE ILIMITADA E A RECIPROCAMENTE CONSTITUÍDA EM UMA ORDEM DE VALIDADE
}

\author{
Aline de Almeida Silva Sousa ${ }^{1}$
}

RESUMO: Este estudo é voltado para análise de prognósticos de recuperação das relações responsáveis, tanto através, como para além do direito, que nos são oferecidos por três condutores. O primeiro é Emmanuel Levinas, no seu compromisso com a responsabilidade ilimitada, mas que não deixa de elucidar a necessidade de comparabilidade. O segundo por Jacques Derrida, que convoca uma abertura para a responsabilidade ilimitada através da desconstrução, na sua experiência aporética de justiça. E, por fim, Castanheira Neves, preocupado com uma unidade integradora de sentido para o direito, concebe a responsabilidade jurídica nas relações de reciprocidade interpessoais.

Palavras-Chave: Ética; Responsabilidade Ilimitada, Reciprocidade; Justiça; Validade.

FROM ETHICS TO JUSTICE THROUGH LAW: BETWEEN UNLIMITED RESPONSIBILITY AND RECIPROCALLY CONSTITUTED RESPONSIBILITY IN A VALIDITY ORDER

ABSTRACT: This study aims to analyse the prognoses of recuperation of responsible human relations, through and beyond the Law, that are offered to us by three conductors. The first is Emmanuel Levinas, in his commitment to unlimited responsibility, but he does not fail to elucidate its interruption by the need for comparability. The second, by Jacques Derrida, who claims an open to the unlimited responsibility through deconstruction, on its aporetic experience of justice. And finally, Castanheira Neves, who is concerned with an integrative unity of meaning of the Law, conceives legal responsibility in reciprocal interpersonal relations.

Keywords: Ethics; Unlimited Responsibility; Reciprocity; Justice; Validity.

\footnotetext{
${ }^{1}$ Mestranda em Ciências Jurídico-Filosóficas na Faculdade de Direito da Universidade de Coimbra - UC. Advogada.
} 


\section{INTRODUÇÃO}

A responsabilidade vem sempre implicada nas questões de Justiça. Não sem razão, pois, vários diagnósticos demonstram que certas injustiças decorrem, ora por uma certa mitigação, ora por uma hipertrofia da responsabilidade. Não obstante, o Direito não é ausente nesta discussão, muito pelo contrário, assume um papel fundamental na mediaçãosistematização das relações de responsabilidade, que não deixam de vir relacionadas às questões de autonomia, de liberdade e igualdade. Desta feita, este estudo passa por diversos prognósticos, que intentam compreender o papel da responsabilidade na realização da Justiça, da Justiça através do/como Direito.

Primeiramente, convoca-se Emmanuel Levinas, que nos oferece diagnósticos que nos levam a repensar toda a tradição filosófica ocidental e a privilegiar aquilo que foi negligenciado nela. Por esta razão, a responsabilidade é tomada como prognóstico fundamental, e não deixa de ser fundamento e condição de possibilidade para o Direito, mesmo que como experiência de conexão/tensão entre a alteridade e a necessidade de comparação (LEVINAS, 2006). Em um segundo momento, traz-se Jacques Derrida, na medida em que mantém seus pontos de contato com o primeiro condutor para a acentuar a experiência aporética da responsabilidade, na impossibilidade de contornar as aporias decorrentes da relação entre Justiça como Desconstrução e o Direito, no seu próprio modo de assumir a tensão entre alteridade e comparabilidade. (DERRIDA, 2003). Por fim, chama-se Castanheira Neves (2011), na medida em que não mantém pontos de contato tão acentuados com a segunda proposta, mas sim com a primeira, no modo como põe as relações de reconhecimento entre as pessoas como condição fundamental do próprio Direito. Mas também porque privilegia a busca por uma unidade integradora de sentido, autônomo, que não deixa de estar aberto aos problemas e circunstâncias histórico-culturais que desafiam o sistema jurídico.

Desta feita, pretende-se estabelecer um diálogo entre tais vias de recuperação das relações humanas responsáveis através, ou mesmo para além do direito, nas suas tensões comuns entre a abertura para justiça da alteridade e a incontornável necessidade da justiça da comparabilidade. Logo, para a realização deste estudo, utilizou-se ampla revisão bibliográfica, para serem analisadas através de uma metodologia dialética, de orientação comparativa, dialógica e crítica dos pensamentos convocados. 


\section{LEVINAS E A RESPONSABILIDADE ILIMITADA COMO VIA INCONDICIONAL PARA A RESPONSABILIDADE JURÍDICA}

Para fins introdutórios, opta-se por iniciar com a clarividente síntese de Fernanda Bernardo sobre o percurso tomado por Emmanuel Levinas: "da responsabilidade ao problema, da justiça à justiça, da responsabilidade ética à responsabilidade ético-jurídico-política" (BERNARDO, 2000, p. 64), que não deixa de ser também o caminho percorrido neste estudo. Todavia, é necessário compreender antes, ainda que de forma muito breve, o pano de fundo deste pensamento, que parte da crítica à tradição filosófica ocidental, pois tem como primado a Ontologia, que se desdobra como a "arte de assimilar o Outro teoricamente" (TIMM DE SOUZA, 1999, 21). Dito de outro modo, trata-se de uma abordagem do pensamento filosófico que tende a anular as diferenças, reduzindo-as à uma ordem totalizante, que nas palavras de Levinas (1980, p. 31) consiste em "uma redução do Outro ao Mesmo, pela intervenção de um termo médio e neutro que assegura a inteligência do Ser”. Nestes termos, a história do ocidente é lida como expressão do pensamento de Heráclito, no qual a guerra é tida como a própria expressão de toda a realidade, pois na guerra não se permite conceber o outro na sua exterioridade, mas apenas nesta totalidade (LEVINAS, 1980, p. 9-10). A importância prática disto é compreendida por Levinas na medida que os "indivíduos reduzem-se aí a portadores de formas que os comandam sem eles saberem" (LEVINAS, 1980, p. 10). Ou seja, o sentido impessoal dado nesta ordem total, pretensamente neutra, esconde um centro decisório, dominador, em torno de um objetivo último. (LEVINAS, 1980, p. 10).

O clímax dessa tradição é atribuído ao pensamento heideggeriano, na medida em que a compreensão do ente, sujeito humano, está sujeita primeiro à compreensão do seu ser, o que implica a subordinação humana à existência compreendida de forma anônima e neutralizada, numa afirmação do primado da liberdade em detrimento da Ética (LEVINAS, 1980, p. 32). Entretanto, apesar de não haver espaço para explorar de forma satisfatória a reação crítica de Levinas ao pensamento de Heidegger, importa mencionar que o nosso condutor foi fortemente influenciado pelo mesmo, inclusive pelo fato de ter participado da sua vida estudantil, juntamente com E. Husserl, em Estrasburgo. A obra Ser e Tempo (Sein und Zeit) foi certamente muito importante para Levinas, sendo um dos cinco livros mais belos da filosofia (LEVINAS, 2000, p. 35).

Neste sentido, o nosso condutor confronta severamente tal abordagem, recusando completamente a subordinação dos entes ao Ser, bem como a liberdade enquanto "deixar-ser", na medida em que o Outro não é e não pode ser mero objeto do conhecimento, pois, seguido as 
palavras de Levinas: "a relação com o outro não ocorre nos limites da ontologia. O vínculo com o outro não é reduzível à sua representação, mas a sua invocação, invocação que não é precedida pela compreensão.” (LEVINAS, 1998, p. 7). É preciso, na realidade, dirigir-se ao Outro, falar com ele, para dar chance para a experiência da proximidade e do acolhimento (LEVINAS, 1998, p. 6).

Pulando uma série de etapas para finalmente ir direto ao ponto, o prognostico que se põe como via para fora deste modelo totalizante, apesar de ainda se fazer nos termos da linguagem filosófica, é o de subordinar todo o pensamento à ética, ou seja, de fazer da Ética a filosofia primeira, na medida em que o encontro com outro acontece antes da ontologia (LEVINAS, 1999, p. 97). O acesso ao rosto é a própria porta entrada da ética (LEVINAS, 2000,

p. 71-72), para a verdade, através de uma aspiração transcendente, em seu desejo em torno da exterioridade (LEVINAS, 1980, p. 49-50). O rosto, portanto, é anterior a qualquer conhecimento ou fenômeno em geral, anterior à mediação pelo mundo (LEVINAS, 2000, p. 71), e se apresenta para nós num olhar que nos interpela como uma súplica exigente, no seu direito de nos exigir tudo. O Outro é, portanto, o Mestre do Eu (LEVINAS, 1980, p. 62). O rosto é concebido também como uma abertura para o divino, para além de toda dominação, como via de recuperação da Metafísica, que é identificada à própria relação ética. As relações sociais são, portanto, o caminho que leva à Deus (ao infinito), o que não se confunde com o conhecimento de Deus separado, como encarnação tematizada (LEVINAS, 1980, p. 64-65).

Desta feita, desde o primeiro momento em que o rosto nos interpela, ele exige responsabilidade, antes mesmo que seja possível dar-se conta disto. A responsabilidade vai muito além do que um faz, do que o diz respeito. O rosto é aquilo que diz respeito. A responsabilidade, deste modo, é condição da própria subjetividade, e não um simples atributo, e se constitui através de uma ordem de irrenunciável obediência (LEVINAS, 2000, p. 89-91).

Neste sentido, o acolhimento do rosto é assumido por Levinas como um dos significados que ele atribui a experiência da Justiça, na qual se busca a própria verdade (LEVINAS, 1980, p. 58). Ou melhor, nas palavras de Fernanda Bernardo (2000, p. 67) “a justiça começa por outrem [...], diante da qual, assimetricamente, o sujeito é absolutamente obrigado - obrigado à responsabilidade ilimitada. O justo é o homem hiper-responsável [...]”. Trata-se de pôr em questão a própria liberdade, a fim de assumir uma outra liberdade, que não é produto da racionalidade, mas identificada à própria exigência de responsabilidade (LEVINAS, 1980, p. 283-284). A liberdade para assumir a Ética como Filosofia Primeira. Trata-se de uma responsabilidade messiânica, infinita, inspirada no judaísmo, na qual a que não 
pode ser anulada nem por ato divino. Nesta experiência, a justiça social cruza o caminho da justiça divina, onde todos são responsáveis por todos (LEVINAS, 1997, p. 19-21). Entretanto, não podemos esquecer do terceiro, que “observa-me nos olhos de outrem” (LEVINAS, 1980, p. 190), e que nos abre para toda a humanidade (LEVINAS, 1980, p. 190), para o próximo do outro - o terceiro -, e junto com ele todos os demais. Deste modo, nos aparece desde já a inevitabilidade de comparar as unicidades. "O Julgamento e a Justiça são exigidos a partir do momento em que o terceiro aparece". (LEVINAS, 1998, p. 202-203).

Revela-se, portanto, uma ambuiguidade sobre o modo em que a Justiça é concebida. Primeiramente, como já notamos, Levinas elucida a experiência da justiça como acolhimento infinito do rosto, que me interpela antes de qualquer racionalização. Mas, como já se viu de forma sucinta, o terceiro, imediatamente, vem a implicar a exigência de uma relação ética também entre todos os outros. Questionado sobre tal ambiguidade por H. Heering, Levinas (1998b, p. 82) responde, aproximadamente, que para que seja possível a responsabilidade desinteressada, exclui-se a reciprocidade, entretanto, não se deve agir sem devoção pelo terceiro. Na relação com o outro, já se está sempre já com o terceiro, que é também o meu próximo. É neste momento que a proximidade se torna um problema, o problema do nosso percurso levinasiano. É necessário se comparar, sopesar e racionalizar entes dotados de unicidade. Assim sendo, a Justiça está muito mais referida à relação com o terceiro do que com o outro, pois na própria epifania do rosto, o terceiro já nos interpela.

Eis, portanto, o problema da Justiça com a entrada do terceiro. Entretanto, não é exatamente esta entrada do terceiro que interrompe o acolhimento do rosto, mas a tercialidade (tertialité) que promove tal interrupção, que segundo Derrida, age "como uma testemunha (tertis) feita para suportar testemunhar o dual do face-a-face, o singular acolhimento da unicidade do outro" (DERRIDA, 1999, p. 29). Há, nesta ocasião, a introdução de uma interrupção-contradição no dizer, que começa com o terceiro, limite da minha responsabilidade e introdutor da questão da justiça, uma questão da consciência, que se faz necessária pelo fato de não se poder negligenciar todos os outros. Presume-se a exigência de comparação, coexistência, contemporaneidade, ordenação, assimilação, intelecção, sistematização, copresença em pé de igualdade perante uma corte julgadora (LEVINAS, 2006, p. 157), o que vem a ser a própria exigência de institucionalização da tercialidade (AROSO LINHARES, 2007, p. 21), onde as partes, igualmente merecedoras e dotadas de questões juridicamente relevantes, apresentam-se diante do juiz (terceiro imparcial) mediador desta relação. Neste sentido, a tercialidade, segundo Aroso Linhares (2007, p. 25) “[...] condena-nos a submeter os 
rostos nus ás "formas plásticas" da "representação" e da "objetividade". [...] nos obriga a comparar os únicos e incomparáveis e escolher entre eles".

Pode-se entender, portanto, que na proximidade, há o dizer sem problemas; na responsabilidade pelo outro e pelo terceiro há a exigência sistemas inteligíveis, ou seja, a ordem do dito. Em outros termos, o terceiro vem mesmo a introduzir a necessidade de assimilação na ordem do Ser e, no Ser mesmo, a hora da sua suspensão. Trata-se, portanto, de conceber a tematização do dito a partir das bases da imediata proximidade com o outro. (LEVINAS, 2006, p. 157-158).

Nestes termos, a justiça nasce deste "ser para o outro", significação de todas as demais relações, e por isto não se pode dizer que o Estado ou o Direito podem ser meros artifícios regulatórios das massas. Isto seria uma justificação tautológica do Estado na lógica do próprio Estado, ou seja, a lógica de um Estado Totalitário (LEVINAS, 2006, p. 159). Desta feita, Levinas (1998, p. 229) anuncia a "hora da justiça, da comparação dos incomparáveis que estão agrupados por espécies e genus. A hora das instituições empoderadas para julgar, [...], da Lei Universal que é sempre dura lex, e dos cidadãos em igualdade perante a lei”. Trata-se mesmo da "hora do Ocidente! A hora da Justiça - requerida, entretanto, pela caridade." (LEVINAS, 1998, 229). Com efeito, é em nome da responsabilidade pelo Outro, anunciada pelo rosto, é que a Justiça se mobiliza. Sejam quais forem os limites do Direito, estes devem revistos pelo infinito amor e benevolência diante do outro. Trata-se de "uma justiça a ser sempre aperfeiçoada diante da sua própria dureza”. (LEVINAS, 1998, p. 229).

É possível ponderar, portanto, que a própria excelência deste projeto se dá através da democracia, que recorre ao incessante remorso da justiça, sempre a revisitar suas legislações e projetos inacabados, na possibilidade de melhorá-los (LEVINAS, 1998, 229), em torno da sua perfectibilidade que é buscada como uma Utopia (LEVINAS, 1998, p. 231). Entretanto, é possível perguntar, como já foi perguntado, se a própria existência do amor não tornaria o Estado de Direito dispensável, como dispôs Aristóteles em "Ética à Nicômaco". Todavia, Levinas responde que "a caridade é impossível sem a justiça, e a justiça é impossível sem caridade" (LEVINAS, 1998, 120-121).

Por outro lado, importa reconhecer, com auxílio de Aroso Linhares (2007, p. 34- 35), que a presente proposta não se aprofunda diante do problema do Direito, e nem nas suas estruturas de inteligibilidade, e corre o risco de o relegar às experiências de prescrições e decisões contingentes. Tal experiência poderia tomar rumos múltiplos, revelando uma incapacidade de manter-se vinculada à proximidade originária. 


\section{A DESCONSTRUÇÃO E O DIREITO EM DERRIDA: SOBRE A EXPERIÊNCIA APORÉTICA DA RESPONSABILIDADE ILIMITADA}

Derrida, no texto chamado "Do Direito à Justiça" lido em 1989 na abertura do colóquio "Desconstruction and the possibility of Justice", insere o movimento da responsabilidade ilimitada na dinâmica da decisão judicial, que concebida como uma experiência aporética, que só pode ser justa na sua impossibilidade, pelas vias da desconstrução (DERRIDA, 2003).

Contudo, antes é preciso ressaltar que o pano de fundo de Derrida é um tanto diferente da voz conduta do ciclo passado. Este vem a identificar uma história logocêntrica para a tradição filosófica ocidental, fundada numa "metafísica da presença", que se constitui como uma série de oposições hierárquicas, em que um certo privilégio é atribuído para um dos lados desta oposição, reconhecendo-lhe uma certa presença, uma certa verdade, em detrimento do outro termo, que é relegado à ausência, ao diferimento, à distância desta mesma verdade (BALKIN, 1987, p. 5-6). Neste sentido, há um claro privilégio da phoné, tendo em vista a assumida proximidade com a logos, e o rebaixamento da escrita, em razão do seu distanciamento (DERRIDA, 1973, p. 9).

Entretanto, a desconstrução, na sua capacidade de reverter argumentos, vem a elucidar que a fala não é realmente mais próxima da logos, na realidade, ela não deixa de ser outro sinal, outra representação, assim como a escrita, igualmente turva e ambígua. (BALKIN, 1987, p. 17). Desta feita, numa atitude de desconstrução absoluta da presença da fala, e da presença mesma, Derrida (1973, P. 194-195) elucida que: "não há fora-de-texto [...] nunca houve senão suplementos, significações substitutivas que só puderam surgir numa cadeia de remessas diferenciais [...] ". Assim sendo, não pretendendo ocultar a multiplicidade de sentidos relacionados, a desconstrução (ou desconstruções) realizada(s) nas cenas de leitura vem a pôr em causa os limites do logocentrismo, a partir de mobilização de um descentramento que possibilita a insurgência do outro sentido e da diferença. (NASCIMENTO, 2004, p. 38).

Finalmente, passado por tais pressupostos, poderemos entrar na temática da responsabilidade pelo outro, e imediatamente pelo terceiro (DERRIDA, 1999, p. 110), como movimento em torno da justiça (como desconstrução), através e para além do direito (DERRIDA, 2006, p. 220). Para isto, segue-se os caminhos nada lineares percorridos por Derrida no texto "Do Direito à Justiça", lido na abertura do referido colóquio organizado por Drucilla Cornell na Cardozo Law School, em Outubro de 1989. (DERIDA, 2003, p. 7). 
Em tal ocasião, o pensador vem a enfrentar o seguinte problema: "será que a desconstrução assegura, permite, autoriza a possibilidade da justiça?” (DERRIDA, 2003, p. 10). Antes de mais nada, Derrida atesta firmemente que as preocupações com a Justiça estão sim na centralidade dos textos identificados como descontrustivistas, ainda de que maneira mais ou menos oblíqua (DERRIDA, 2003, p. 15-19). Neste sentido, após um longo dialogo com Pascal e Montaigne sobre a força (enforce) autorizada do Direito, necessária para a realização da Justiça, que por sua vez é necessária como fundamento do Direito justo, leva-o ao encontro com o fundamento místico da autoridade, denunciando a ausência de fundamento de tal violência no seu momento fundador e o seu limite. .Desta feita, Derrida vem a identificar o Direito, em sua essência, como desconstrutível, porque construído e fundado a partir de textos interpretáveis e transformáveis, bem como pelo fato do seu último fundamento não ser fundado, o que não deixa de ser uma abertura para as próprias transformações políticas ao longo da história. (DERRIDA, 2003, p. 19-25).

É esta, portanto, a estrutura desconstrutível do direito, do direito em torno da justiça, da justiça do direito, possível pela desconstrução. Ainda, importa alertar que a justiça, por si mesma, para além do direito, não é desconstrutível, tal como a própria desconstrução (DERRIDA, 2003, p. 25-26). Por este caminho, Derrida culmina então na célebre frase “ $a$ desconstrução é a justiça" (DERRIDA, p. 26). Logo, pode-se inferir, juntamente com Derrida (2003, p. 26) três preposições: "a desconstrutibilidade do direito (por exemplo) torna a desconstrução possível” (DERRIDA, 2003, p. 26); “a indesconstrutibilidade da justiça que torna a desconstrução possível, confunde-se mesmo com ela” (DERRIDA, 2003, p. 26); e consequentemente: "a desconstrução tem lugar no intervalo que separa a indesconstrutibildiade da justiça e desconstrutibilidade do direito. Ela é possível como experiência do impossível, aí onde, mesmo se ela não existe, se não esta presente, ainda não ou jamais, há justiça”. (DERRIDA, 2003, p. 26).

Neste caminhar, a nossa voz condutora vem a perceber duas coisas: a primeira é que tal experiência é, na verdade, uma travessia, uma viagem para um destino através de uma passagem. Entretanto, se for possível encontrar uma passagem, não há experiência de aporia. Conclusivamente, a justiça seria experiência daquilo que não se dá pela experiência, pois não possui caminho. Entretanto, Derrida também acredita que não há Justiça sem esta experiência da aporia (DERRIDA, 2003, p. 27). “A justiça é uma experiência do impossível” (DERRIDA, 2003, P. 28). Deste modo, no âmbito da decisão judicial, segundo Derrida (2003, p. 28), “de cada vez que se aplica tranquilamente uma boa regra a um caso particular, [...] o direito encontra 
aí, [...], a sua conta, mas podemos ter certeza de que a justiça nunca encontra aí a sua”. Trata- se de conceber o direito como calculável, ao contrário da justiça, o incalculável, porém necessária na medida em que o momento da decisão judicial, situado entre o justo e o injusto, nunca garante a justiça através da aplicação de uma regra. (DERRIDA, 2003, p. 28).

Enfim, chegamos a questão mais emblemática da tentativa de se pensar justiça através do direito: como conciliar a justiça da alteridade, do outro - e também do eu como outro - através de uma regra geral? (DERRIDA, 2003, p. 29). É impossível pensar nesta questão com total segurança, na medida em que se endereçar para o outro - condição de possibilidade para a Justiça - é também tarefa rigorosamente impossível. Não se pode falar na língua do outro sem antes o assimilar conforme a lei de um terceiro implícito nesta relação, inclusive, tal possibilidade é excluída pelo direito, pois este requer universalidade no idioma. Logo, parece justo buscar um idioma que seja capaz de ser interpretado e compreendido por todos os sujeitos, em sentido lato, embora tal coisa não seja possível. Esta forma de injustiça supõe que o outro, vítima desta injustiça linguística, seja capaz de falar uma língua em geral. Esbarar-se, desta maneira, numa exigência de reinterpretação de todos os limites da criteriologia paraconfrontar este tipo de violência, pondo em causa a centralidade do sujeito humano, homem, branco, europeu, adulto, carnívoro, como medida da justiça. (DERRIDA, 2003, p. 29-32).

Nesta atitude reinterpretativa, primeiramente, é necessário ir em torno da responsabilidade ilimitada, incalculável, na medida em que nos revela os limites do direito e seus institutos já sedimentados. E, sobre a justiça propriamente dita, importa convocar a responsabilidade que vem a estar no âmago da desconstrução, comprometida com a exigência de justiça infinita diante das singularidades, mesmo em face (ou em razão) da sua pretensão de universalidade. É necessário, nestes termos, manter-se constantemente aberto ao problema das questões fundamentais da justiça, nos limites de suas acepções teóricas, que nada tem a ver com a neutralização da temática, mas com o exercício de responsabilidade e atenção hiperbólica. (DERRIDA, 2003, p. 32-33).

Desta feita, alerta-se para o fato de que o momento de suspensão de um termo/axioma através da desconstrução - epokhé -, é um momento de desorientação necessária ao problema da justiça. Esta possibilidade de suspensão deve permanecer estruturalmente presente exercício de toda e qualquer responsabilidade, no intuito de protege-la de umarigidez dogmática negativa de si própria, pois é o próprio lugar de abertura para as transformações jurídico-políticas, motivadas pela exigência de suplemento da justiça, em sua excessiva desproporção. Nestes termos, a desconstrução vem a colher a sua força numa incessante 
insatisfação que dá causa às transformações exigentes destes suplementos. (DERRIDA, 2003, p. 34). Há, deste modo, uma dinâmica em que o direito pretende se realizar em nome da justiça, e a justiça através e para além do direito. É nesta relação que a desconstrução tem o seu lugar, na instabilidade, nesta ausência fixa de lugar (DERRIDA, 2003, p. 36-37). E para demonstrar tal relação, importaria comentar algumas aporias.

A primeira aporia, já comentada inclusive, é chamada de "epokhé da regra", que se refere ao evento da justiça ou injustiça a ser realizada por meio de uma ação ou decisão, que pressupõe um ser livre e responsável. Um ser que não possui liberdade não pode ser responsável considerado responsável por uma decisão, portanto, não poderá estar agindo de forma justa ou injusta. Todavia, para que uma decisão seja tomada como justa, mesmo em sua liberdade, deve ter vínculo com uma lei ou regra prescrita, na ordem do calculável e numa preocupação com a equidade Logo, uma decisão justa, para que assim seja, não pode ser tomada através de um cumprimento acrítico de uma regra, mas no seu dever de confirmar o seu valor, aprovando-a, interpretando-a em cada caso. A sentença, apesar de ter de ser conforme à lei pré-existente, necessita de uma interpretação re-inventiva e restauradora, capaz de chamar a justiça, numa atitude contrária à simples conservação do direito. Cada caso é recebido como único, exigente de uma interpretação singular, logo, nenhuma regra é autossuficiente para abarca-lo. Entretanto, se o juiz parar no indecidível, não se dirá que agiu de forma justa. Desta feita, conclui Derrida com este paradoxo que em momento algum se poderá dizer, presentemente, que uma decisãoé puramente livre e responsável, portanto, puramente justa. Em vez da justiça, poderá se referir apenas à adequação e a convencionalidade do direito. (DERRIDA, 2003, p. 38).

Já a segunda aporia é a "assombração do indecidivel”, que nos impõe a reconhecer que uma decisão que não passa pela indecibilidade não é livre, pois se reduz a seguir os caminhos prescritos de aplicação da ordem do calculável. Mas no momento de suspensão do indecidível ainda não há justiça, porque só uma decisão pode ser justa (DERRIDA, 2003, p. 40). Deste modo, passada a prova de indecidibilidade, a decisão retorna a ser realizada nos termos da regra dada e reinventada, logo, não pode ser presentemente ou plenamente justa. Todavia, a indecidibilidade deve estar presente em toda a decisão, não sendo possível ultrapassá-la ou revela-la. (DERRIDA, 2003, p. 40-42).

Já a terceira aporia diz respeito à tensão existente entre a urgência da decisão e o horizonte do saber. Derrida mantêm uma clara reserva diante dos horizontes reguladores de justiça em geral, na medida em que são horizontes (DERRIDA, 2003, p. 43). Estes representam, ao mesmo tempo uma abertura e o limite da Justiça, "quer num progresso infinito quer em uma 
espera”. (DERRIDA, 2003, p. 44) Entretanto, para Derrida (2003, p. 44) a Justiça não espera, embora também nunca seja possível obter todas as informações desejáveis para a realização de uma decisão plenamente justa. Por sua vez, na prudência e no saber sem limites (se houvesse), a decisão chegaria muito tarde; e na urgência e precipitação, agir-se-ia no não-saber. Em suma, é em razão do transbordamento excessivo da interpretação através de um ato performativo, que não deixa de buscar o ato constatativo, e em razão da urgência estrutural da justiça, que não há para ela regulador messiânico ou horizonte de espera. A justiça, talvez tenha, um porvir, que não um futuro certo, pois não pode ser presumida em termos racionais do presente. Isto implica dizer que há um "talvez" para a justiça, pois excede a ordem do calculável, das regras, das antecipações e entre outras presunções teoréticas. (DERRIDA, 2003, p. 44-46).

Todavia, Derrida alerta que este excesso de justiça em relação ao direito não pode servir como álibi para a distância ou recusa das instituições estatais nas lutas jurídico-políticas, pois quando esta ideia de incalculável é abandonada a si, está sempre vulnerável à apropriação para o cálculo mais perverso. Entretanto, para Derrida, não há segurança absoluta contra este risco, inclusive pela sua recusa dos horizontes, sob pena de saturar a abertura do apelo à justiça. Ademais, não se pode isolar dentro de fronteiras seguras o campo jurídico dos demais campos da vida social (DERRIDA, 2003, P. 46). Portanto, para além de calcular e negociar esta relação, é preciso fazer isto para das zonas já identificadas "da moral, da política ou do direito, para além do nacional e o internacional, o público e o privado, etc.” (DERRIDA, 2003, p. 47). Tratase de convocar o direito em torno de um ideal emancipatório político, a ser também posto em questão, neste mesmo movimento de abertura para as zonas secundárias marginais que denunciam uma violência operante (DERRIDA, 2003, p. 48). Todavia, não se pode deixar de identificar, juntamente com Aroso Linhares, que tal perspectiva vem identificar a materialidade do direito como as contingentes vontades políticas (AROSO LINHARES, 2007, p. 35-37). Vêse a seguir o desenvolvimento de tal crítica.

\subsection{Sobre a interpelação crítica, que não deixa de ter com Derrida, de Aroso Linhares.}

Não podemos deixar de perceber que o modelo de direito que Derrida vem a pôr em causa o presume, unicamente, na sua referência às regras, a ordem da legalidade e as prescrições textuais de modo geral, como se só se pudesse perceber o direito nestas circunstâncias (AROSO LINHARES, 2007, p. 43). Desta feita, seguindo as percepções de Aroso Linhares (2007, p. 44-45), Derrida, ao “absolutizar” a ordem do calculável e identificar 
nela algumas das condições de inteligibilidade da "aporia da justiça", vem também a absolutizar as intenções do Direito e a predeterminar a sua busca à incontornável reprodução da relação aporética entre direito e justiça. Deste modo, a função seletiva atribuída às oposições categoriais e à epistemologia da presença acaba por impedir a inscrição da juridicidade num outro modelo, numa outra significação. (AROSO LINHARES, 2007, p. 44-45).

Nestes termos, Aroso Linhares (2007, p. 44-45) compreende que Derrida identifica o direito à contingência material das suas prescrições, a serem inscritas/dissolvidas através do tempo, numa dinâmica de interpenetração dos diversos campos que não possuem fronteiras asseguradas, em busca da justiça como promessa de transformação, no seu compromisso político de emancipação, o que não é senão reproduzir a aporia da relação justiça/direito. E tais aporias elucidadas por Derrida só fazem sentido se confundirmos o momento de experimentação de uma norma-critério com a execução de uma estratégia política, controlável a partir do exercício de "aplicação" e justificação de uma regra.

Desta feita, , trata-se de um "diagnóstico nos leva a experimentar os limites da desconstrução [...] que permanece prisioneira do "sistema" que desconstrói... e das oposições categoriais que este sistema legitima" (AROSO LINHARES, 2007, p. 46), pois vincula o direito à metafísica da presença sem nos oferecer uma possibilidade interna, renunciando-a e saltando para além dela, em torno de uma voluntas política. Identifica-se, portanto, uma abertura arriscada, que torna o direito suscetível ao livre domínio pelas forças históricas, que poderia significar uma regressão ao sistema desconstruído ou em curso de desconstrução. (AROSO LINHARES, 2007, p. 46-47).

\section{O DIREITO COMO A ALTERNATIVA HUMANA EM CASTANHEIRA NEVES: SOBRE A RESPONSABILIDADE DA PESSOA EM UMA ORDEM DE VALIDADE}

Entramos agora em uma rota diversa da percorrida anteriormente, justamente para pôr em causa os pontos de partida assumidos, no intuito de nos confrontar agora com uma possibilidade de assunção da responsabilidade delimitada no campo do direito, bem como para explicitar as razões para isto. Trata-se perseguir uma intenção condutora historicamente constituenda nas relações intersubjetivamente dialogantes, axiologicamente comprometidas com um certo contexto histórico-cultural, no qual o direito se constitui enquanto alternativa para um problema necessário, o problema da convivência humana na partilha de um único mundo, um problema de suum cuique tribuere, mas que não recusa uma abertura diante do problema e a vulnerabilidade do outro. (AROSO LINHARES, 2007, p. 47-48). Contudo, 
para

refletirmos sobre o porquê do direito em vez das outras alternativas (CASTANHEIRA NEVES, 2011), e de que forma a responsabilidade vem a ser essencial neste compromisso interno de uma ordem de validade, teremos de nos debruçar sobre as condições de emergência do direito, a fim de distinguir aquilo que fundamentalmente o determina como direito e o seu sentido. Trata-se apenas de uma alternativa, dentre outras, tendo em vista que só haverá direito enquanto certas condições de emergência se fizerem presentes, sendo que apenas uma desta se faz essencial. (CASTANHEIRA NEVES, 2008).

Desta feita, a primeira a ser enfrentada vem a ser a condição mundanal, que nos alerta para a unicidade do mundo que abriga uma pluralidade de indivíduos conviventes. Esta relação vem a ser a condição básica da realização da própria existência humana, que implica uma participação plural e o acesso pela mediação de uns através dos outros. Trata-se de uma experiência de inter-subjectividade, que exige a reciprocidade na modulação dos comportamentos, o que implica a possibilidade de se exigir do outro uma atitude prevista nos termos desta relação, posto que não é possível habitar no mundo sem poder fazer exigências aos outros, e vice-versa. Desta feita, na antecipação das constantes faltas diante da fruição e, na própria previsão de que irão ocorrer faltas, a possibilidade de fazer exigências é o que nos permite supri-las. Eis aqui uma expressão da Justiça para Castanheira Neves. (2008, p. 13-15).

É possível já traçar a incontornável diferença entre a moral e o direito para Castanheira Neves. A moral é muito mais exigente, vem como um imperativo diante do outro e de todos os outros, como na ética de Levinas, na qual a interpelação do rosto, que não é acessado pela mediação do mundo, como um comando irrecusável de responsabilidade infinita. De outro modo, o direito também tem uma exigência, contudo, vem a ser convocada numa relação de "bilateralidade atribuitiva", que convoca a existência de direitos e deveres correlativos, que se constituem através da relações inter-pessoais de partilha do mundo. (CASTANHEIRA NEVES, 2008, p. 15).

Já a segunda condição é a antropológico-existêncial, que nada mais é do que o reconhecimento da autonomia humana diante do meio, que permite ao homem constituir-se enquanto sujeito capaz de debruçar-se sobre a realidade, no intuito de interroga-la e compreendê-la, e assim, transcendê-la (CASTANHEIRA NEVES, 2008, p. 17). De outro modo, o transcender também se realiza em torno de uma ideação, num projetar-se para forado mundo e do presente, "ao futuro e como o futuro." (CASTANHEIRA NEVES, 2008, p. 17). Este apelo em torno da possibilidade do ser é o que vem a ser designado como valor - 
exigência de um dever-ser. Desta feita, importa reconhecer que da condição existencial vem a culminar na própria condição axiológico-normativa. (CASTANHEIRA NEVES, 2008, p. 19).

Numa outra via, vale reconhecer que o homem não vive sozinho, mas num "sercom-outros", condição de existência humana e da humanidade como um todo que só se realiza através de uma experiência comunitária, histórico-culturalmente determinada, participada através da palavra e linguagem. Contudo, a convivência comunitária nunca deixa de estar sob a ameaça constante da desintegração, levada a cabo pelas divergências que nos separam. Mas é através da experiência da institucionalização culturalmente assumida que se empreende esforços para que isso não aconteça. Esta vem a ordenar as relações e os objetivos sociais, no intuito de impedir os dois extremos entre a orientação objetiva da sociedade e a livre realização da personalidade. (CASTANHEIRA NEVES, 2008, p. 19-29).

Por sua vez, embora estas duas condições até agora descritas se verifiquem como necessárias, estas não são capazes de distinguir o direito enquanto direito, haja vista que há uma série de outras institucionalizações que não são ordens de direito. Um exemplo disto são as experiências estatais que submetem o sujeito ao puro despotismo da ordem da necessidade (CASTANHEIRA NEVES, 2011, p. 301), que se apresenta como ordem irrecusável e com premissas totalizantes que intentam autojustificar-se, ora como se fosse uma necessidade da natureza (Hobbes), ora da história-espírito (Hegel), bem como história-produção (Marx) e entre ouras. Já outras alternativas colhem fundamentos nas ordens de possibilidades (organizacionais, bem como científico-tecnológicas) ou de finalidades (em torno de objetivos puramente políticos). O direito, na realidade, distingue-se das demais ordens e emerge enquanto direito quando presente a condição ética. (CASTANHEIRA NEVES, 2008, p. 31).

Por sua vez, o direito pressupõe uma ideia de normatividade, que se manifesta histórico-culturalmente, quando os homens reciprocamente se reconhecem, nas suas relações de indisponibilidade axiológica e de exigências normativas. Nestas relações, eles se constituem como sujeitos de direitos, na condição de destinatários deste, bem como sujeitos do direito, como titulares dos mesmos. O reconhecimento mútuo desta comunidade sujeitos pessoas, vem a ser mesmo condição transcendental do direito enquanto tal. Todavia, é necessário atentar para o fato de que a categoria de pessoa - "um fim em si" de inviolável dignidade, nos termos kantianos -, segundo Castanheira Neves, é uma atribuição feita em termos axiológicos, e não ontológicos, portanto, depende da relação de respeito (Kant) e de reconhecimento (Hegel). (CASTANHEIRA NEVES, 2008, p. 31-34). Tal reconhecimento deverá ser reciproco. Ou como melhor diz Castanheira Neves (2008, p. 36): “só um ser de dignidade pode conferir 
sentido de dignidade [...] ao seu acto de reconhecimento e esse ser de dignidade, por seu lado, apenas o é pelo reconhecimento dos outros". Assim sendo, o reconhecimento deste dever de respeito diante da pessoa em sua inviolável dignidade vem a ser o "imperativo ético do direito", que não deixa de ser uma expressão de amor ao próximo. Isto não implica dizer que o direito se confunde com a ética, mas que este tem uma dimensão ética como condição fundamental de possibilidade. (CASTANHEIRA NEVES, 2008, p. 36).

A partir das relações de mútuo reconhecimento e respeito entre as pessoas, é possível inferir a exigência do princípio da igualdade, na medida nenhuma pessoa vale mais que outra e, se valesse, haveria a autorização para a dominação de uma por outra, o que retiraria a própria condição de pessoa (CASTANHEIRA NEVES, 2008, p. 37). Contudo, não significa que não há diferenças concretas que justifiquem um tratamento desigual, como a vulnerabilidade que atinge as questões de raça, gênero, classe e entre outras. Ademais, importa esclarecer que só há aparente incompatibilidade entre a igualdade e a liberdade se entendermos esta última em seu sentido meramente negativo, como se fosse uma deliberada ausência de impedimentos, e a primeira reduzida à uma perspectiva de igualitarismo. Na realidade, ambas estão implicadas uma na outra (CASTANHEIRA NEVES, 2011b, p. 216), "pois se a igualdade se pode dizer a condição social da liberdade, a liberdade é uma possibilidade pessoal que só será universal se todos nela se reconhecerem como iguais ou se nenhum for já privilegiado já diminuído nessa possibilidade". (CASTANHEIRA NEVES 2011b, p. 216).

Na realização da nossa liberdade implicada pela exigência de igualdade, somos não só titulares dos nossos próprios direitos, mas também estamos investidos de deveres diante dos outros e da comunidade na qual participamos. Somos responsáveis pela constituição desta comunidade, na sua totalidade de intenções e valores, num compromisso com as indisponíveis referências axiológicas que dão validade e sentido para as nossas relações (CASTANHEIRA NEVES, 2008, p 38). Por sua vez, a responsabilidade interpela a pessoa como um compromisso objetivado, a ser realizado por ela, culminando no imperativo de correlatividade entre direitos e de deveres. (CASTANHEIRA NEVES, 2008b, p. 152-153). Conclusivamente, “o reconhecimento que obtenho dos outros confere-me direitos - afirmações de mim excluídas do arbítrio dos outros -; o reconhecimento que os outros obtêm de mim impõe deveres - exigências que dos outros me convocam excluídas ao meu arbítrio". (CASTANHEIRA NEVES, 2008b, p. 153). A pessoa, portanto, está investida de responsabilidade.

Neste sentido, são vários e distintos os níveis de responsabilidade. Há a responsabilidade perante a humanidade - como princípio da responsabilidade, ou seja, diante 
de cada homem-pessoa, bem como numa solidariedade diante do Ser e da humanidade em nós, inclusive do ser-futuro, enquanto possibilidade de realização do sentido último da humanidade. Perante o outro - como relação ética, relação direta, sem mediação, de pessoa para pessoa, da forma como pensou Levinas, como ordem de obediência que nos exige o acolhimento puro, numa ausência de mediação e de tematização, que vem a instaurar o privilégio do outro e o esquecimento de mim. Ainda, há o terceiro nível, que consiste na responsabilidade perante os outros pela mediação social, que é a a responsabilidade através do direito, do direito como validade, como ordem de validade. Isto significa dizer que o que distingue o direito como direito é a exigência de fundamento para as pretensões dos outros e para as minhas, manifestadas nas relações intersubjetivas. A validade se constitui através de um fundamento, de um sentido normativo, que pode ser em forma de princípios ou valores que transcendem o ponto de vista individual. Busca-se uma certa unidade de sentido integrante através de determinações justificadas, que emergem nas relações entre os membros de uma comunidade que se reconhecem reciprocamente como iguais. (CASTANHEIRA NEVES, 2008b, p. 153-155).

Esta unidade integrante não pode ser buscada apenas em termos formais, como no imperativo categórico kantiano. Exige-se fundamentação material, histórico-culturalmente determinada. Esta exigência é decorrente da própria realização e existência da pessoa enquanto sujeito ético, dotada de liberdade, igualdade e responsabilidade, na sua assunção de deveres diante dos outros, e na titularidade de direitos próprios que impedem os arbítrios dos outros. Assim sendo, o direito, enquanto ordem de validade, necessariamente emerge dos fundamentos axiológicos-normativos constituídos nas relações entre sujeitos-pessoas, e tem como referência última a realização da dignidade (CASTANHEIRA NEVES, 2008b, p. 155). É por todas estas razões que o direito vem a ser a alternativa humana (CASTANHEIRA NEVES, 2011, p. 289), na medida em que se constitui histórico-culturalmente em torno da realização dos sujeitospessoas, que comprometem-se conjuntamente com responsabilidades, objetivadas nas relações de correspondência entre direitos e deveres. (CASTANHEIRA NEVES, 2008b, p. 155)

Importa ressaltar, que a responsabilidade é delimitada nas dimensões positivas e negativas da juridicidade. As dimensões positivas são as que tornam possíveis a realização da pessoa. Nestes termos, é possível inferir uma "índole aberta do sistema intencional" (CASTANHEIRA NEVES, 2011c, p. 415), visto que é a partir das relações inter-pessoais que o direito é constituendo, logo, não estão definidas as possibilidades histórico-sociais de 
realização e constituição do direito, o que já nos previne de certos problemas de realização concreta, na medida em que a solução do problema-caso fica sempre aquém das suas exigências, em razão do dinamismo histórico-social (CASTANHEIRA NEVES, 2011c, p. 415-416). Já as dimensões negativas, de modo contrário, postulam limitações e proibições normativas em face das antagônicas intencionalidades. Com efeito, é incontornável a imposição de limites para estes limites, a fim de impedir que a limitação de uns possa culminar no privilégio de outros, o que resultaria num sacrifico da igualdade pela responsabilidade (CASTANHEIRA NEVES, 2011c, p. 416). Nestes termos, é possível deduzir outros dois princípios destes limites, o primeiro é o princípio do mínimo, na medida em apenas os impedimentos indispensáveis para a realização pessoal de todos na vida comunitária podem ser considerados como válidos; e o princípio da formalização, que vem atestar a exigência de uma institucionalização formal dos limites materiais traçados através do princípio do mínimo, a fim de possibilitar o seu concreto cumprimento. Tratam-se, portanto, de critérios delimitativos da juridicidade, para que a mesma não se dilua nas demais alternativas que já falamos a pouco. Esta delimitação tem uma verdadeira importância concreta, na medida em que apenas em certas situações, em específicos modos de relacionamento entre as pessoas, em um determinado contexto, se poderá identificar quando se está diante ou não de um problema-caso jurídico a demandar uma decisão judicativa a partir da valoração autônoma do decidente, que colhe seus fundamentos no sentido do direito e nos critérios que vem a selecionar, recusando uma mera aplicação em termos dedutivos. A decisão judicial está implicada por uma irrecusável responsabilidade concreta, pois o julgador, em sua autonomia decidente, é responsável pela realização do sentido último da juridicidade. (CASTANHEIRA NEVES, 2013, p. 234).

Entretanto, Marmelstein Lima (2013, P. 412-417) alerta para o fato de que tal confiança na responsabilidade da função jurisdicional, que concede ao juiz a posição de mediação da convivência ética, capaz de assimilar e realizar os valores comunitários sem uma contaminação pelos fatores político-ideológicos pode ser um tanto quanto demasiada utópica, tendo em vista as demonstrações ao longo da história das conexões entre o poder político, econômico e a atividade judicativa. Entretanto, vale perceber que a perspectiva jusrisprudencialista de Castanheira Neves não tem pretensões meramente analítico-descritivas do direito e da atividade jurisdicional, mas críticas. Importa pensar o direito, a atividade judicativa, numa orientação por uma ideia regulativa, por um "dever-ser", em torno de uma referência axiológica material. Do contrário, qualquer norma positiva cultural poderia ser assimilada de forma acrítica, e não faria qualquer sentido pensar em referentes de justiça ou 
injustiça, pois todos seriam igualmente válidos.

Desta feita, não se assume aqui uma responsabilidade hiperbólica para o direito, na qual realização da liberdade e da autonomia seria mitigada, o que descaracterizaria a própria responsabilidade; mas uma responsabilidade limitada e delimitada internamente nos espaços do direito, em torno do outro e de mim reciprocamente, que é ao mesmo tempo condição de possibilidade e modo de realização da pessoa enquanto participante de uma comunidade de pessoas. O direito, portanto, é a "alternativa humana" para o problema da partilha do mundo, que tem como referência última a realização da pessoa enquanto sujeito-ético de inviolável dignidade.

\section{CONCLUSÃO}

É em torno do amor por todos que o Direito se constitui enquanto Direito, na indisponibilidade desta condição ética que, apesar de ter o seu fundamento na exigência de acolhimento da unicidade/singularidade, não deixa de acentuar a necessidade de não se negligenciar as demais pessoas que não estão próximas, mas igualmente merecedoras de responsabilidade. Por esta razão, convoca-se a "Hora do Ocidente" e a sua "comparação dos incomparáveis", através da experiência institucional da tercialidade, na qual a responsabilidade é surpreendida com limites, que são extremamente necessários para a realização da dignidade da pessoa, na medida em que, se institucionalmente fosse possível admitir uma hipertrofia da responsabilidade de uns, simultaneamente estaria reduzida a sua liberdade e, consequentemente, fragilizar-se-ia a própria condição de pessoa.

O caminho até agora assumido impõe também que fiquemos alertas diante das soluções do nosso desconstrutivista, visto que Jacques Derrida não deixa de estar preso a um modelo de direito que se diferencia das outras instâncias de organização da vida social apenas através de uma estrutura formal, e ainda deixa de estabelecer um horizonte claro de justiça, que realmente possa pretender assegurá-la de alguma forma.

Já com Castanheira Neves, temos a responsabilidade inserida numa ordem de validade, constituenda histórico-culturalmente através das relações interpessoais numa comunidade de pessoas que se reconhecem por meio de atribuições axiológicas reciprocas. A ordem jurídica, deste modo, põe-se a equilibrar a responsabilidade da pessoa com a liberdade e igualdade, na medida que a hipertrofia ou mitigação de qualquer um destes atributos descaracteriza, de uma forma ou de outra, a condição de pessoa em sua inviolável dignidade, dando abertura para a insurgência das relações de dominação e instrumentalização. Todavia, é 
preciso alertar que tais limites só podem ser delimitados histórico-culturalmente. Logo, pode ser que em determinados contextos a exigência de responsabilidade se faça mais presente, e em outros menos. Desta feita, a experiência de tercialidade desta proposta, preocupada com a autonomia do direito enquanto ordem de validade, não o reduz às prescrições formais, mas considera os seus princípios, e concede ao juiz um papel de central importância para a realização do Direito, sem recorrer aos critérios externos. Entretanto, não se pode deixar de denunciar a confiança excessiva na atividade judicativa, embora não se deva ignorar a sua necessária aspiração em torno de um “dever-ser”.

\section{Referências}

AROSO LINHARES, José Manuel. O Dito do direito e o Dizer da Justiça: Diálogos com Levinas e Derrida. In: Themis: Revista da Faculdade de Direito da UNL. Vol. VIII, n. 14, Coimbra: Janeiro, 2007, p. 5-56.

BALKIN, Jack M. Deconstructive Pratice and Legal Theory. In: 96 Yale L.J. 743. Faculty Scholarship Series. 291, Yale Law Scholarship Repository, 1987, p. 1-48. Disponível em: 〈http://digitalcommons.law.yale.edu/fss_papers/291/>. Acesso em 14 de jun 2018

BERNARNDO, Fernanda. Da responsabilidade ética à ético-político-jurídica: a incondição da responsabilidade ética enquanto incondição da subjetividade segundo Emmanuel Lévinas (II). In: Revista Filosófica de Coimbra, $\mathrm{n}^{\circ}$ 17. Coimbra: Instituto de Estudos Filosóficos Faculdade de Letras da Universidade de Coimbra, 2000, pp.63-95

CASTANHEIRA NEVES, Antônio. Coordenadas de uma reflexão sobre o problema universal do direito - ou as condições de emergência do direito como direito. In: Digesta: Escritos acerca do direito, do pensamento jurídico, da sua metodologia e outros. Vol. 3. Coimbra: Coimbra Editora, 2008, pp. 9-48

CASTANHEIRA NEVES, Antônio. Pessoa, direito e responsabilidade. In: Digesta: Escritos acerca do direito, do pensamento jurídico, da sua metodologia e outros. Vol. 3. Coimbra: Coimbra Editora, 2008b, pp. 129-158.

CASTANHEIRA NEVES, António. O Direito como alternativa humana. Notas de reflexão sobre o problema actual do direito. In: Digesta: Escritos acerca do direito, do pensamento jurídico, da sua metodologia e outros. Vol. 1, Reimpressão Coimbra: Coimbra Editora, 2011, p. $287-310$

CASTANHEIRA NEVES, António. A Revolução e o Direito. In: Digesta: Escritos acerca do direito, do pensamento jurídico, da sua metodologia e outros. Vol. 1, Reimpressão Coimbra: Coimbra Editora, 2011b, p. 51-241.

CASTANHEIRA NEVES, António. Princípio da legalidade criminal. In: Digesta: Escritos acerca do direito, do pensamento jurídico, da sua metodologia e outros. Vol. 1, Reimpressão Coimbra: Coimbra Editora, 2011c, p. 349-373. 
CASTANHEIRA NEVES, Antônio. Metodologia Jurídica. Problemas Fundamentais. STVDIA IVRIDICA. Reimpressão. Coimbra: Coimbra Editora, 2013

DERRIDA, Jacques. Gramatologia. Editora Perspectivas S.A/ Editora da Universidade de São Paulo: São Paulo, 1973.

DERRIDA, Jacques. Adieu to Emmanuel Levinas. Standford University Press: California, 1999

DERRIDA, Jacques. Força de Lei: $O$ fundamento místico da autoridade. Campo das Letras: Porto, 2003

DERRIDA, Jacques. Spectres of Marx. The Stated of Debt, the Work of Mourning and the New International. Routledge: New York and London, 2006

LEVINAS, Emmanuel. Totalidade e Infinito. Lisboa: Edições 70, 1980.

LEVINAS, Emmanuel. Difficult Freedom: Essays on Judaism. Baltimore: Johns Hopkins Paper Backs Edition, 1997

LEVINAS, Emmanuel. Entre Nous: thinking-of-the-other. New York: Columbia Press University, 1998.

LEVINAS, Emmanuel. Of God Who Comes to Mind. California: Standford University Press, 1998 b.

LEVINAS, Emmanuel. Alterity \& Transcendece. London: The Athlone Press, 1999.

LEVINAS, Emmanuel. Otherwise than Being or Beyond Essence. $6^{\text {a }}$ ed. Pittsburg: Duquesne University Press, 2006

LEVINAS, Emmanuel. Ética e Infinito. Madrid: La balsa de la Medusa, 2000.

LIMA, George Marmelstein. A Judicialização da Ética: Um projeto de transformação da ética em direito orientada pela expansão do círculo ético. Tese de Doutoramento em Direito, Justiça e Cidadania no Séc. XXI. Faculdade de Direito da Universidade de Coimbra, 2013. Disponível na internet:

<https://estudogeral.sib.uc.pt/bitstream/10316/24576/2/A\%20Judicializa\%C3\%A7\%C3\%A3o \%20da\%20\%C3\%89tica.pdf >. Consulta em 26 de jun. 2018.

NASCIMENTO, Evandro Batista. Derrida. Coleção passo-a-passo, nº 43, E-book, plataforma Kobo. Jorge Zahar Editor Ltda: Rio de Janeiro, 2004

TIMM DE SOUZA, Ricardo. Sujeito Ética e História: Levinas, o traumatismo infinito e a crítica da filosofia ocidental. Porto Alegre: Coleção Filosofia 82, 1999 